\title{
MOLECULAR GENETICS OF DEVELOPMENT STUDIED IN THE TRANSGENIC MOUSE ${ }^{1}$
}

\section{Heiner Westphal}

Laboratory of Molecular Genetics, National Institute of Child Health and Human Development, National Institutes of Health, Bethesda, Maryland 20892

\section{Peter Gruss}

Department of Molecular Cell Biology, Max-Planck Institute of Biophysical Chemistry, 3400 Göttingen, West Germany

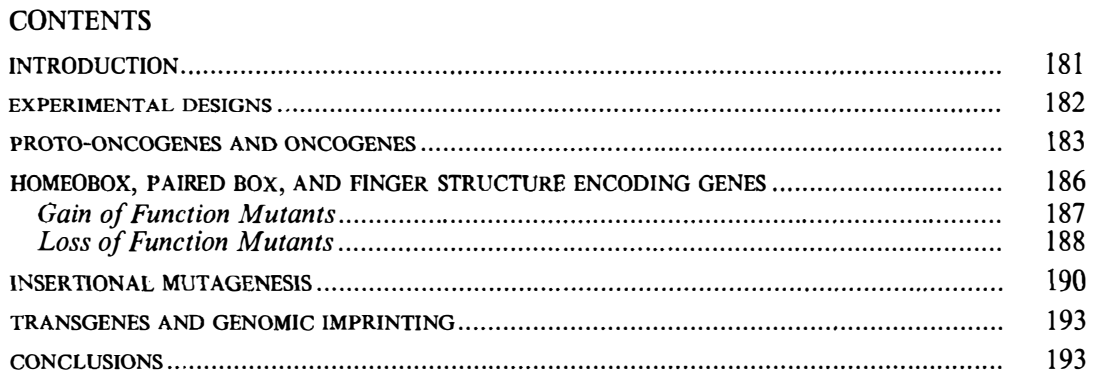

\section{INTRODUCTION}

Transgenic technology allows the insertion of defined genetic material into the germline of mice and other organisms. Of all disciplines of the life

\footnotetext{
${ }^{1}$ The US Government has the right to retain a nonexclusive, royalty-free license in and to any copyright covering this paper.
} 
sciences few stand to profit more from this than developmental biology. Important insights into the molecular genetics of development can be gained either by overproducing factors that regulate or interfere with development in specific target organs of the growing organism, or by mutating resident chromosomal genes that regulate development. While virtually every new phenotype observed in a transgenic mouse also involves changes in some aspect of development, we will deal selectively with broad changes in pattern formation and in organogenesis initiated by genes that have been inserted or changed in the mouse genome. This field of research is very much at its beginning, hence our review will be short. Nonetheless, we hope to elicit in our readers an interest in the enormous potential of these experiments for the understanding of the molecular genetics of mammalian development.

\section{EXPERIMENTAL DESIGNS}

A transgenic mouse is characterized by the presence of foreign DNA sequences inserted in the genome by laboratory techniques. A recent review details this approach (Jaenisch 1988). Most commonly, a transcription cassette is constructed and injected into a pronucleus of a one-cell embryo so that it can integrate in the host chromatin and become part of every cell of the growing organism. This includes the germ line, so that the original transgenic mouse will become founder of a transgenic line. Transgenes appear to integrate randomly by illegitimate recombination events. The spatial and temporal control of expression is influenced by cis-acting regulatory elements incorporated in the construct or present at the integration site.

An alternative method to introduce new genetic material into mice involves the use of embryonic stem (ES) cells. DNA can be introduced into ES cells in culture, the desired transformants can be selected and placed in recipient blastocysts (see Figure 1). The pluripotent ES cells are capable of colonizing all or most of the tissues of the resulting offspring (reviewed by Bradley \& Robertson 1986). If they participate in the formation of germ line chimeras, their specific traits can be propagated. Since this methodology allows a great number of cells to be subjected to selective steps in culture, it holds a great deal of promise for producing mutations at defined loci either by conventional or insertional mutagenesis or by gene replacement via homologous recombination. Initial work focused on a model locus, the gene encoding HPRT or hypoxanthine-guanosine phosphoribosyl transferase. HPRT-deficient mice were produced from ES cells that carried either spontaneous mutations or retroviral inserts in the target gene (Hooper et al 1987; Kuehn et al 1987). The hprt gene is located on 


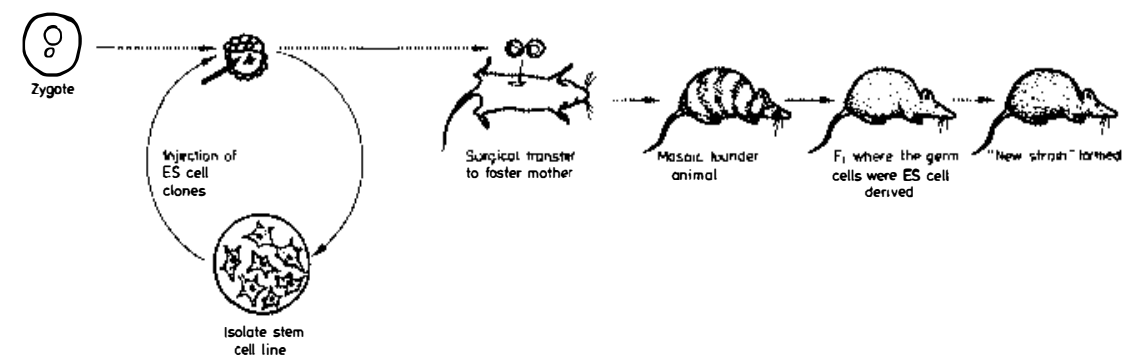

Figure 1 Schematic representation of the generation of transgenic mice using embryonic stem (ES) cells. Pluripotent ES cells can be grown in culture from cells of the inner cell mass of mouse blastocysts (Evans \& Kaufman 1981; Martin, 1981; Bradley et al, 1984). Since large numbers of these cells can be transformed with DNA in culture and subjected to selection, even rare events such as homologous recombination can be detected and the respective cell clone can be isolated. Upon introduction of preselected ES cells into blastocysts and surgical transfer of blastocysts into a foster mother, chimeric animals can be obtained. Provided the ES cell has maintained its pluripotency, transmission into the germ line is possible. Animals can be bred to generate homozygous mice.

the $\mathrm{X}$ chromosome, hence only one mutant copy is needed in male cells to yield a phenotype that can easily be selected. The initial results using the hprt gene as a model established the feasibility of introducing changes in resident chromosomal genes of the mouse. However, most genes of interest are present as diploid copies for which no positive selection procedures exist. We will describe below two different approaches that screen for ES cells that have undergone homologous recombination events in one or another of such nonselectable diploid genes.

\section{PROTO-ONCOGENES AND ONCOGENES}

Cellular proto-oncogenes or viral oncogenes are primarily discussed in the context of cancer and not in the context of embryogenesis. However there is a rapidly growing body of information that assigns cellular protooncogenes a physiologic role in development. The temporal and spatial control of expression, as much as their nature and quantity, determines the outcome of their action. Viral oncogenes or a nonphysiologic dose of cellular proto-oncogenes interfere with development in characteristic ways that can be assessed in the transgenic mouse.

Several laboratories have begun to examine the effects of targeting the expression of defined viral oncogenes or their cellular equivalents in preselected tissues or organs, notably the eye lens, the pancreas, and the mammary gland (most recently reviewed by Cory \& Adams 1988). Inasmuch as these studies are focused on oncogenesis, they will not be 
discussed here. However, this type of experiment can also register the interaction of a specific oncogene or proto-oncogene product with unknown factors that define a specific cell phenotype in the developing organism. The nature and composition of such factors change during differentiation. Therefore, one may predict that the phenotype of transgenic mice expressing a given oncogene will reflect not only the nature of the target tissue but also its developmental stage at the time of initial exposure to the oncogene product. One of our laboratories has developed a system to test this prediction.

With the help of the $\alpha \mathrm{T}$ transgene (a promoter sequence of the murine $\alpha \mathrm{A}$-crystallin gene fused to sequences encoding for the tumor antigens of SV40), we have been able to direct malignant growth to the lens of transgenic mice (Mahon et al 1987). The lens has a simple architecture. At day E11 of gestation, posterior epithelia of the embryonic mouse lens begin to differentiate into crystallin producing fibers that are destined to form the lens nucleus. T. Nakamura et al (in preparation) have recently compared two very different phenotypes of mouse lines carrying the $\alpha \mathrm{T}$ transgene. Line $\alpha \mathrm{T} 1$ accumulates SV40 tumor antigens (TAG) in E11 lens epithelia prior to primary fiber differentiation. Progeny of this line develop fast growing lens tumors comprised of poorly differentiated cells that are largely deficient in lens crystallin synthesis. By contrast, individuals of line $\alpha \mathrm{T} 2$ accumulate TAG at day E12/13 in differentiating fiber cells. Their lens tumors grow very slowly and consist of cells that retain some characteristics of differentiation, including the ability to synthesize significant amounts of crystallins. These observations led us to propose a model that is illustrated in Figure 2. According to this model, the oncogene products immortalize some basic properties of the initial target cell in which they accumulate. In $\alpha \mathrm{T} 1$, the target cells are the embryonic lens epithelia. We postulate that these cells are not yet fully committed to differentiation into fiber cells and hence, they produce no or very little $\beta$ and $\gamma$ crystallins. Their growth regulation has a higher degree of plasticity, which makes them proliferate fast under the influence of the oncogene product. By contrast, the developing lens fiber cells of $\alpha \mathrm{T} 2$ approach terminal differentiation and produce $\beta$ and $\gamma$ crystallins. These cells proliferate more slowly in the presence of TAG and maintain their program of $\beta$ and $\gamma$ crystallin synthesis. Thus it appears that a powerful transforming activity can be modified by the state of differentiation of the cell.

A quite different approach, designed to assess the role of a protooncogene in development, has recently been formulated by Mansour et al (1988), who altered the int-2 gene of ES cells by insertional mutagenesis. Int-2 is a proto-oncogene that displays a highly restricted pattern of expression during mouse organogenesis (Wilkinson et al 1988), which 


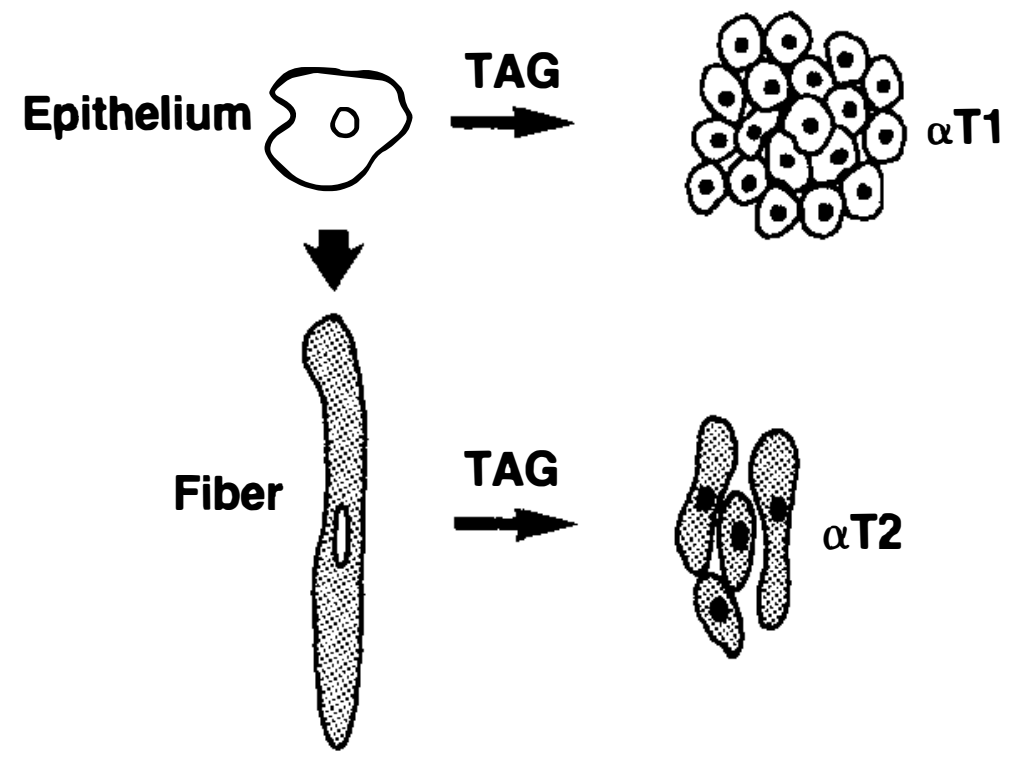

Figure 2 Model of SV40 tumor antigen (TAG) mediated transformation of lens epithelia and fibers in the transgenic mouse. Posterior lens epithelia differentiate (arrowhead) into fibers which begin to synthesize $\beta$ and $\gamma$ crystallins (shaded). In $\alpha$ T1 mice, TAG mediated transformation of undifferentiated epithelia leads to rapid proliferation. In $\alpha \mathrm{T} 2$ mice, differentiated fiber cells undergo transformation and proliferate slowly. Both the $\alpha \mathrm{T} 1$ and $\alpha \mathrm{T} 2$ lens cells contain nuclear TAG (indicated by black color).

suggests important functions in mammalian development. Mansour et al developed an elegant method that enabled them to enhance the selection for cells that have undergone homologous recombination at the int-2 locus. The bacterial neo gene, which confers neomycin resistance, was fused to a promoter active in ES cells. This construct was inserted such that it disrupted the coding sequence of one of the int-2 exons. In addition, a herpes virus gene encoding thymidine kinase (HSV-TK) was linked to one end of the linear DNA fragment to serve as a negative selectable marker. Upon introduction of this DNA construct by electroporation, a method that insures the integration of a limited number of gene copies (Doetschman et al 1988), the drug G418 was added to eliminate all cells that did not integrate and express the neo gene. Surviving cells were treated with the nucleoside analog gancyclovir (GANC). This drug was originally developed as an antiviral agent because it is cytotoxic for cells containing functional herpes virus thymidine kinase. In an illegitimate recombination event the entire linear DNA fragment is integrated and HSV-TK is expressed, 
killing the cell in the presence of GANC. During homologous recombination, however, the DNA sequence encoding HSV-TK is lost, and the cell survives GANC treatment. The method enhances the selection at least 2000-fold for the rare homologous combination event. It is hoped, of course, that the ES cell containing the int-mutation is able to participate in the formation of germ-line chimeras so that mice expressing the mutant trait can be derived.

The example of mice carrying dominant, spontaneous mutations in the c-kit proto-oncogene shows that this approach can lead to interesting developmental phenotypes. Recently c-kit has been identified as the product of the $W$ locus (Geissler et al 1988). White coat color, sterility, and anemia are characteristic for $W$ locus mutants. These phenotypes have been attributed to failure of stem cell populations to migrate and to proliferate properly. The ability to produce defined mutations via homologous recombination will allow the role of proto-oncogenes in mammalian development to be probed in a systematic way. For example, the murine homolog of the c-mos proto-oncogene has been linked to meiotic maturation in frog and mouse oocytes (Mutter et al 1988; Sagata et al 1988; R. Paules et al, in preparation). Targeting the chromosomal mos gene in the mouse germ line could reveal similar and additional functions of mos in mammalian development.

\section{HOMEOBOX, PAIRED BOX, AND FINGER STRUCTURE ENCODING GENES}

The assumption that structural conservation is indicative of functional conservation prompted many researchers to screen mammalian genomes for the presence of sequences first discovered in developmental control genes of Drosophila (McGinnis et al 1984a,b; Scott \& Weiner 1984). To date three gene families classified by common sequence motifs have been identified in the mouse genome. These include the homeobox (Hox), paired box $(P a x)$, and finger structure $(Z p f)$ encoding genes (reviewed by Dressler \& Gruss 1988; Holland \& Hogan 1988).

First indications that these genes may indeed be involved in mammalian developmental control were obtained by studying their temporal and spatial pattern of expression. The homeobox containing genes are expressed in a tissue and region specific manner, the paired box containing gene, $\mathrm{Pax}$ 1 , is expressed along the entire rostro-caudal axis in segmented structure, and a finger containing gene, $M k r 2 / Z p f 2$, is expressed specifically in neurons (see Holland \& Hogan 1988; Dressler \& Gruss 1988, for review).

Investigation of a mouse mutant, undulated (un), strongly supported 
the view that these conserved genes play a role in development. Un exhibits abnormalities of the vertebral column beginning during embryonic development (Grüneberg 1954) and the adult has distortions along the entire rostro caudal axis. Pax 1 is expressed in the structures affected by the mutation (Deutsch et al 1988; Balling et al 1988). Thus, it was rewarding to find that in un mice there is a glycine for serine substitution in the most conserved region of the paired box of Pax 1, which suggests that this mutation is causing the developmental defect (Balling et al 1988). Although the identification of $u n$ as a gene controlling mammalian development was made possible by analyzing a preexisting mouse mutant, it is unlikely that mutants for all the members of the above mentioned gene families will be found. Thus alternative approaches, including the generation of dominant gain of function or loss of function mutations, must be explored.

\section{Gain of Function Mutants}

A temporally or spatially misdirected expression during embryogenesis may result in phenotypic alterations and consequently help us to define the role of genes involved in developmental control. Using a large genomic fragment including the putative control signals and the coding region of Hox 1.4, Wolgemuth \& collaborators (1989) generated several lines of transgenic mice. The rationale was that, by insertion of one or more additional copies of the gene, a finely tuned control mechanism could be thrown out of balance in the tissue in which this gene is normally expressed. Indeed, all transgenic animals overexpressed the Hox 1.4 gene in testis as well as in the intestinal tract. In midgestation embryos the level of transgene transcripts was at least fivefold higher, particularly in the gut. Interestingly, a phenotype identified as megacolon developed most likely as a consequence of the activity of the transgene. Mouse mutants exhibiting the megacolon phenotype show a deficiency of myenteric ganglion cells in the colon. These represent neural crest derivatives that migrate into the developing gut (Figure 3).

In a related type of experiment, Balling et al (1989) used a DNA construct in which the $\beta$-actin promoter was placed upstream of the Hox 1.1 coding region in order to express the Hox 1.1 gene at ectopic sites. Several founder animals were obtained. One of them was used to breed transgenic offspring. The transgenic offspring remained small, did not feed and died soon after birth most likely due to a phenotype known as cleft-palate. These mice show a number of craniofacial abnormalities, including open eyes at birth, non-fused pinnae, and cleft secondary palate. This phenotype resembles the effects observed after application of retinoic acid during pregnancy (retinoic acid embryopathy). Because of the similarity in phenotypes, it has been suggested that cranial neural crest cells that participate 


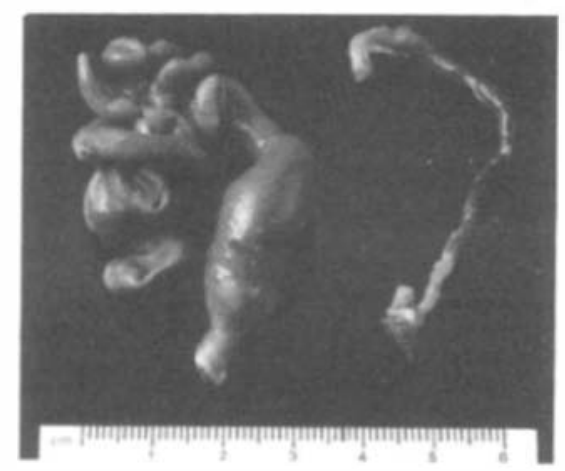

Figure 3 Mouse mutants exhibiting the megacolon phenotype and showing a deficiency of myenteric ganglion cells in the colon. (With permission, Nature 337: 464-67 copyright (C) 1989. Macmillan Ltd.)

in the formation of the distorted structures may represent a target of Hox 1.1 ectopic expression (Balling et al 1989). Again, the phenotype could be correlated with the activity of the transgene. In parallel experiments using the histocompatibility gene $\mathrm{H} 2$ promoter to activate the Hox 1.1 gene, no transgenic offspring have been obtained (R. Balling et al, personal communication), which suggests lethal effects due to the ectopic expression of Hox 1.1 during embryogenesis.

\section{Loss of Function Mutants}

Certain mutant gene products can exert dominant negative effects on development by competing with the wild-type product. Resulting phenotypes in which gene function is blocked at the protein level were first described as antimorphs (for review, see Herskowitz 1987). The possibility to supply mutant gene products via transgene insertion and thereby interfere with development in the mouse was realized by Stacey et al (1988). These authors aimed at generating a mouse model of a human genetic disease, osteogenesis imperfecta type II, which is associated with substitutions of single glycine residues in $\alpha 1$ (I) collagen. A mutant collagen gene was inserted in the germ line of transgenic mice. As little as $10 \%$ mutant gene expression in these mice can disrupt normal collagen function, presumably by interfering with the formation of the multimeric structure of genuine collagen. The resulting dominant lethal phenotype with its severe skeletal abnormalities resembles the human disease. In another example of dominant negative gene regulation on the protein level, mutant forms of a viral transcriptional activator have recently been shown to interfere with the action of their wild-type counterpart (Friedman et al 1988). 
By analogy, the role of genes encoding putative transcription factors, such as homeobox containing genes, could be probed by expression of a nonfunctional equivalent gene. The products of these genes may be involved in a hierarchy of transcriptional regulation, which ultimately establishes the embryo pattern. Expression of a mutant form of one of the members in the hierarchy should lead to a disturbance in pattern formation (see Levine \& Hoey 1988 for review). Similarly, transgenes encoding mutant products of a wide variety of mouse genes may eventually be expressed in the embryo in order to assess the function of their wild-type corollaries during development.

Dominant loss of function can also be induced by antisense RNA. RNA complementary to messenger RNA has been shown to repress the expression of specific genes in mammalian cells (Weintraub et al 1985; Melton 1985; Izant \& Weintraub 1985) and in Drosophila embryos where it induces a specific mutant phenotype (Rosenberg et al 1985). Thus, antisense expression in transgenic mice provides a tool to functionally inactivate a target gene and thereby possibly induce a mutant phenotype. This approach has been used by Katsuki et al (1988) to convert normal behavior to shiverer (shi) by antisense expression in transgenic mice. Mice homozygous for the mutation show a violent shiver when disturbed. This phenotype is due to a deficiency in myelin basic protein (mbp) (Roach et al 1983; Kimura et al 1985; Molineaux et al 1986). Katsuki and coworkers (1988) consequently inserted a myelin basic protein cDNA into an expression vector in the reverse orientation. This expression vector promotes transcription from the mbp gene promoter, carries a splicing signal from the rabbit $\beta$ globin gene, and a polyadenylation signal from SV40. Several transgenic offspring of a founder transgenic mouse were converted from the normal to the shi phenotype. It was demonstrated that antisense messenger RNA was expressed in these mutant mice, which allowed the conclusion that the phenotypic alterations probably were the result of expression of antisense mbp RNA. In a related type of experiment Strickland \& coworkers (1988) showed that the synthesis of tissue plasminogen activator can be blocked by injection of cognate antisense RNAs into maturing oocytes.

Finally, loss of function of developmental control genes can be achieved using targeted mutagenesis. We have already discussed this approach in the context of proto-oncogenes. One of our laboratories has targeted the Hox 1.1 gene of the mouse ES cell. An oligonucleotide linker, 20-base pairs long, was inserted into the coding region of the second exon of Hox 1.1 (Kessel et al 1987) causing a frame-shift mutation (Zimmer \& Gruss 1989). The construct was placed by microinjection (Capecchi 1980) directly into the nucleus of ES cells. After a few growth cycles, the cells were screened with the help of the PCR, or polymerase chain reaction (Saiki et 
al 1985). This highly sensitive technique can detect an event of homologous recombination even if it occurs in only one of a pool of cells (Kim \& Smithies 1988). For the PCR reaction, an oligonucleotide identical to the one we inserted in the Hox 1.1 gene was used as primer 1. Primer 2 is an oligonucleotide that is complementary to a sequence located directly upstream of the target site of homologous recombination (Figure 4). Amplification of the sequence between primer 1 and primer 2 leading to a fragment of the expected size will occur only in the case of a homologous recombination event. Using this protocol, 1 of 150 injected cells was shown to carry a homologously recombined mutated allele. This remarkably high frequency readily allowed the subcloning of the respective cell. In the future, we foresee a variation of this protocol. Instead of the introduction of the oligonucleotide, the insertion could equally well be designed to produce a single point exchange, an approach that should also be suitable for somatic gene therapy. Currently, many laboratories are attempting to utilize ES cell lines in order to generate chimeric mice. So far, several groups have succeeded in producing animals that are mosaics and thus descended from both the foster blastocyst and the ES cells introduced. Although previous experiments have demonstrated that ES cells trans-
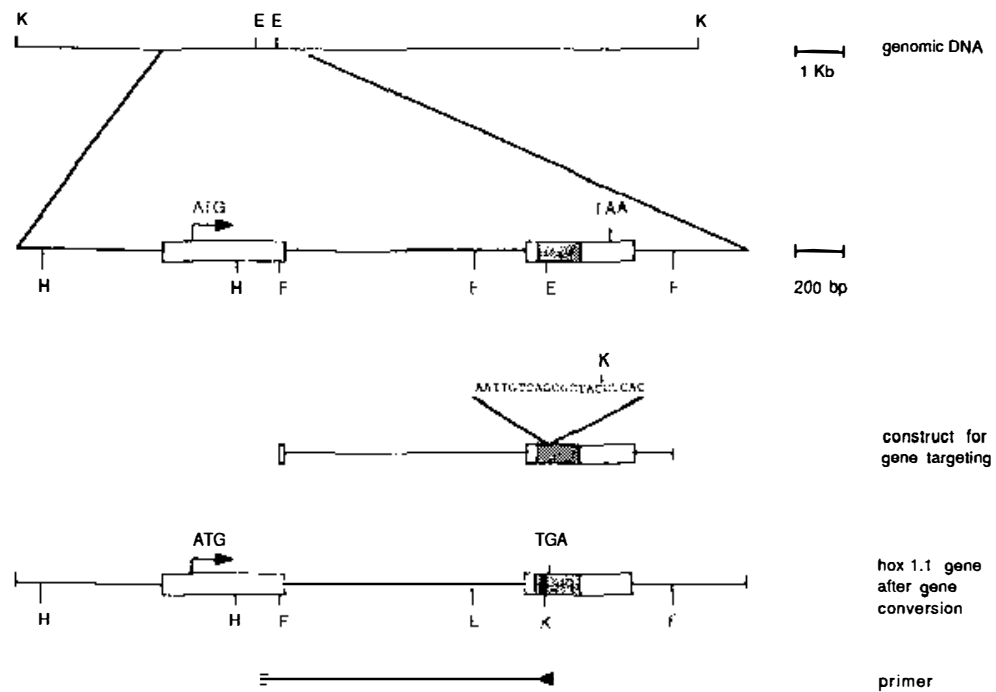

Figure 4 Schematic representation of the mutagenesis of the Hox 1.1 gene and its analysis by PCR. A 20 bp oligonucleotide was inserted into the Eco RI (E) site of a Fsp I (F) fragment and subsequently used for microinjection into ES cells as a construct for gene targeting. The successful homologous recombination event was monitored using PCR; as primer 1 the 20 bp oligonucleotide, and as primer 2 a sequence specific for the Hox 1.1 site located upstream of the Fsp I fragment was used (Zimmer \& Gruss 1989). 
fected in vitro can be transmitted through the germ line, there is so far only one report on germ line transmission of ES cells carrying a gene altered by homologous recombination (Thompson et al, 1989). Based on previous experience, however, it can only be a question of time until this promising method will enable researchers to introduce mutations into a variety of genes of the animal and to analyze their effect on developmental control.

\section{INSERTIONAL MUTAGENESIS}

Insertion of transgenes in chromosomal DNA can cause mutations if functions of essential genes are disrupted. Typically, these mutations are recessive and result in noticeable phenotypes with an estimated frequency of 5-10\% (Jaenisch 1988). They often interfere with development and, in severe cases, cause embryonic lethality. One well-characterized mouse mutant, Mov 13, carries a retroviral insert in the first intron of the $\alpha 1$ (I)collagen gene. This mutant is being utilized to investigate the role of collagen in development (reviewed by Jaenisch 1988).

Sometimes transgene insertion brings about defects that are allelic with known spontaneous mutants. Examples include $l d$ or limb deformity and $d t$ or dystonia musculorum. The ld mutation in mice homozygous for transgene insertion affects genes involved in the regulation of organogenesis. Development of transgenic ld limb buds is impaired as early as day E10 of embryogenesis. Kidney development is also affected. Using the transgene fortuitously integrated in $l d$, genomic sequences were cloned and used to characterize $l d$ cDNAs. Transcription of the normal $l d$ gene begins as early as the egg cylinder stage, and transcripts are also found in adult tissues. One of these transcripts contains an open reading frame for a protein of 1468 amino acids. Transcription is quantitatively and qualitatively altered in $l d$ mutants, as would be expected from an insertion event that interrupts $l d$ gene function (Woychik et al 1985 and in preparation).

Homozygous individuals of the transgenic mouse line allelic to $d t$ lose limb coordination shortly after birth and die young. The histological picture shows a specific loss of dorsal root sensory axons along the spinal cord. The fact that the transgene interrupting the $d t$ locus contains a lac $Z$ transcriptional cassette was utilized to obtain stained preparations of the neural tube, which showed $\beta$-galactosidase activity beginning at day E9.5 in the rostral-most region, and involving the entire length of the neural tube by day E13.5. Thus it is likely that the transgene has come under the control of cis-acting regulatory sequences of the $d t$ locus (Kothary et al 1988). With the help of the inserted lac $Z$ sequence, it should therefore be possible to characterize the $d t$ gene at the molecular level. 
Following work in other systems, Allen et al (1988) have utilized the excellent properties of lac $Z$ as an in situ tracer of gene activity in their design of a general method aimed at detecting genes that are involved in mammalian organogenesis and pattern formation. They microinjected into mouse embryos a lac $Z$ transcription cassette that lacks active $c i s$-acting elements conferring strong spatial or temporal control of expression. If this cassette happens to integrate at a site controlled by a strong promoter that is active in specific cell systems of the developing organism, lac $Z$ will also be expressed in these cells from the allele in which it integrated. Indeed, sections obtained from transgenic embryos revealed unique patterns of $\beta$-galactosidase staining that were symmetrically arranged, and affected organs and tissues that differed from one integration event to the other. The result is best explained by postulating that the transgene integrated into one of a number of chromosomal regions actively expressed during development. The lac $Z$ reporter gene thus came under the control of hitherto unknown genes involved in the regulation of pattern formation. Such genes can now be traced with the help of the integrated lac $Z$ sequence.

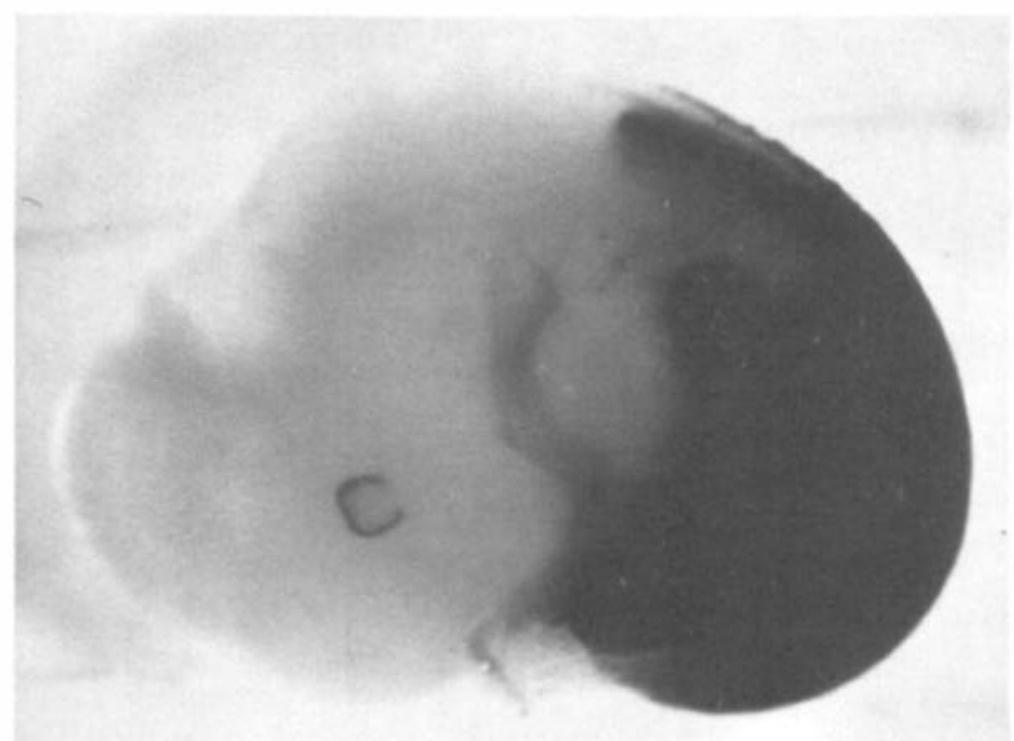

Figure 5 Expression of a Hox 1.1 promoter-lacZ fusion gene in a transgenic day E11.5 embryo. Transgenic mice were generated using a Hox 1.1 promoter-lac $Z$ fusion gene. Day E1 1.5 embryos were fixed in $1 \%$ formaldehyde, $0.2 \%$ glutaraldehyde, $0.02 \% \mathrm{NP} 40,1 \times \mathrm{PBS}$, washed twice in PBS and stained in $1 \mathrm{mg} / \mathrm{mlX}-\mathrm{Gal}, 5 \mathrm{mM} \mathrm{K}_{3} \mathrm{Fe}(\mathrm{CN})_{6}, 5 \mathrm{mM} \mathrm{K}_{4} \mathrm{Fe}(\mathrm{CN})_{6}$, $2 \mathrm{mM} \mathrm{MgCl} 2,1 \times$ PBS. Expression of the transgene is detectable in spinal ganglia, neural tube, mesoderm, and epidermis. 
One of our laboratories has used the $\beta$-galactosidase enzymatic activity as a reporter in order to map the tissue-specific control elements of a Hox 1.1 homeobox containing gene. In these experiments the coding region of Hox 1.1 was replaced by the coding region of $l a c Z$, which placed it under the transcriptional and post-transcriptional regulation of Hox 1.1 control elements (Figure 5). This construct was introduced into zygotes and transgenic mouse lines were established and bred. Analysis of the resulting embryos by using the conventional X-gal stain, revealed the presence of $\beta$-galactosidase activity. As shown in Figure 5, a distinct spatial expression pattern was obtained in the central nervous system, as well as in sclerotomes and the mesodermal component of several organs (A. Püschel \& P. Gruss, in preparation). The overall temporal and spatial expression pattern was similar if not identical to the expression of the endogenous Hox 1.1 gene as studied by in situ analysis (Mahon et al 1988).

\section{TRANSGENES AND GENOMIC IMPRINTING}

Both classical genetic experiments (Searle \& Beechey 1978; Searle \& Beechey 1985; Cattanach \& Kirk 1985; Cattanach 1986; Solter 1987) and nuclear transfer experiments have demonstrated that a genomic contribution from both the mother and the father is essential for successful development (McGrath \& Solter 1984; Surani et al 1984; McGrath \& Solter 1986; Mann \& Lovell-Badge 1984; Renard \& Babinet 1986; Surani et al 1986a,b; Surani 1987; Monk 1987). These data further revealed that the paternal genome seems to be more important for development of extraembryonic tissues, while the maternal genome plays a greater role for embryonic development. Since the maternal and paternal genetic contributions do not function equivalently during development, differential genome imprinting must occur during female and male gametogenesis.

If a transgene integrates into a chromosomal locus subject to genomic imprinting, it can be used as a molecular marker to examine the molecular details of this phenomenon. Since in appropriate crosses the transgene is inherited either from the mother or from the father, it is subject to imprinting during maternal or paternal gametogenesis. It was demonstrated that methylation of a given transgene is accurately switched between the maternal and the paternal pattern (Reik et al 1987; Sapienza et al 1987). Moreover, expression studies using the transgene RSV-myc as a probe revealed that the expression is strictly dictated by its paternal origin (Swain et al 1987). Only the transgenic alleles inherited from the male parent were expressed, while the same transgene inherited from the female parent was not. Interestingly, the transgene inherited from the father was under- 
methylated. Thus there is a correlation between the degree of methylation and the activity or inactivity of a gene. These elegant experiments clearly document differential imprinting imposed on the genetic material during gametogenesis, and the molecular details involved are under investigation.

\section{CONCLUSIONS}

Our review points out various approaches toward defining genes that regulate mammalian genes and ways to modify their action in the transgenic mouse. In addition, we discuss experiments that probe the interrelationship between development and oncogenesis. The power of transgenic technology has already brought fascinating results and is about to provide us with entirely new insights into the molecular genetics of mammalian development.

\section{ACKNOWLEDGMENTS}

We thank Dr. Kathleen Mahon and Dr. Corrinne Lobe for valuable comments and Mrs. Kathy Shoobridge for typing the manuscript. P. G. acknowledges financial support by the Max-Planck Society and the Deutsche Forschungsgemeinschaft.

\section{Literature Cited}

Allen, N. D., Cran, D. G., Barton, S. C., Hettle, S., Reik, W., et al. 1988. Transgenes as probes for active chromosomal domains in mouse development. Nature 333: 852-55

Balling, R., Deutsch, U., Gruss, P. 1988. Undulated, a mutation affecting the development of the mouse skeleton, has a point mutation in the paired box or Pax 1. Cell 55: 531-35

Balling, R., Mutter, G., Gruss, P., Kessel, M. 1989. Cranofacial abnormalities induced by ectopic expression of the homeobox gene Hox 1.1 in transgenic mice. Cell. In press

Bradley, A., Evans, M., Kaufman, M. H., Robertson, E. 1984. Formation of germline chimeras from embryo-derived teratocarcinoma cell lines. Nature 309: 25556

Bradley, A., Robertson, E. 1986. Embryoderived stem cells; a tool for elucidating the developmental genetics of the mouse. Curr. Top. Dev. Biol. 20: 357-71

Capecchi, M. R. 1980. High efficiency transformation by direct microinjection of DNA into cultured mammalian cells. Cell

22: 479-88

Cattanach, B. M. 1986. Parental origin effects in mice. J. Embryol Exp. Morph. 97: 137-50 (Suppl.)

Cattanach, B. M., Kirk, M. 1985. Differential activity of maternally and paternally derived chromosome regions in mice. Nature 31 5: 496-98

Cory, S., Adams, J. M. 1988. Transgenic mice and oncogenesis. Annu. Rev. Immunol. 6: 25-48

Deutsch, U., Dressler, G. R., Gruss, P. 1988. Pax 1, a member of a paired box homologous murine gene family, is expressed in segmented structures during development. Cell 53: 617-25

Doetschman, T., Maeda, N., Smithies, O. 1988. Targeted mutation of the Hprt gene in mouse embryonic stem cells. Proc. Natl. Acad. Sci. USA 85: 8583-87

Dressler, G. R., Gruss, P. 1988. Do multigene families regulate vertebrate development? Trends Genet. 4: 214-19

Evans, M. J., Kaufman, M. H. 1981'. Establishment in culture of pluriopotential cells from mouse embryos. Nature 292: 154-56

Friedman, A. D., Triezenberg, S. J., McK- 
night, S. L. 1988. Expression of a truncated viral trans-activator selectively impedes lytic infection by its cognate virus. Nature 335: 452-54

Geissler, E. N., Ryan, M. A., Housman, D. E. 1988. The dominant-white spotting(W) locus of the mouse encodes the $c$-kit protooncogene. Cell 55: 185-92

Grüneberg, H. 1954. Genetical studies on the skeleton of the mouse. XII. The development of undulated. J. Genet. 52: 44155

Herskowitz, I. 1987. Functional inactivation of genes by dominant negative mutations. Nature 329: 219-22

Holland, P. W. H., Hogan, B. L. M. 1988. Expression of homeobox genes during mouse development: a review. Genes Dev. 2: 773-82

Hooper, M., Hardy, K., Handyside, A., Hunter, S., Monk, M. 1987. HPRTdeficient (Lesch-Nyhan) mouse embryos derived from germline colonization by cultured cells. Nature 326: 292-95

Izant, J. G., Weintraub, H. 1985. Constitutive and conditional suppression of exogenous and endogenous genes by anti-sense RNA. Science 229: 345-52

Jaenisch, R. 1988. Transgenic Animals. Science 240: 1468-74

Katsuki, M., Sato, M., Kimura, M., Yokoyama, M., Kobayashi, K., et al. 1988. Conversion of normal behavior to shiverer by myelin basic proteins antisense cDNA in transgenic mice. Science 241: 593-95

Kessel, M., Schulze, F., Fibi, M., Gruss, P. 1987. Primary structure and nuclear localization of a murinehomeodomain protein. Proc. Natl. Acad. Sci. USA 84: 5305-10

Kim, H. S., Smithies, O. 1988. Recombinant fragment assay for gene targeting based on the polymerase chain reaction. Nucleic Acids Res. 16: 8887-903

Kimura, M., Inoko, H., Katsuki, M., Ando, A., Sato, T., et al. 1985. Molecular genetic analysis of myelin-deficient mice: shiverer mutant mice show deletion in gene(s) coding for myelin basic protein. J. Neurochem. 44: 692-96

Kothary, R., Clapoff, S., Brown, A., Campbell, R., Peterson, et al. 1988. A transgene containing lac $Z$ inserted into the dystonia locus is expressed in neural tube. Nature 335: 435-37

Kuehn, M. R., Bradley, A., Robertson, E. J., Evans, M. J. 1987. A potential animal model for Lesch-Nyhan syndrome through introduction of HPRT mutations into mice. Nature 326: 295-98

Levine, M., Hoey, T. 1988. Homeobox proteins as sequence-specific transcription factors. Cell 55: 537-40
Mahon, K. A., Chepelinsky, A. B., Khillan, J. S., Overbeek, P. A., Piatigorsky, J., et al. 1987. Oncogenesis of the lens in transgenic mice. Science 235: 1622-28

Mahon, K. A., Westphal, H., Gruss, P. 1989. Expression of mouse homeobox gene Hox 1.1 during mouse embryogenesis. Development 104: 187-95 (Suppl.)

Mann, J. R., Lovell-Badge, R. H. 1984. Inviability of parthogenones is determined by pronuclei, not egg cytoplasm. Nature 310 : 66-67

Mansour, S. L., Thomas, K. R., Capecchi, M. R. 1988. Disruption of the proto-oncogene int-2 in mouse embryo-derived stem cells: a general strategy for targeting mutations to non-selectable genes. Nature 336: 348-52

Martin, G. R. 1981. Isolation of a pluripotent cell line from early mouse embryos cultured in medium conditioned by teratocarcinoma stem cells. Proc. Natl. Acad. Sci. USA 78: 7634-38

McGinnis, W., Garber, R. L., Wirz, J., Kuroiwa, A., Gehring, W. J. 1984a. A homologous protein-coding sequence in Drosophila homeotic genes and its conservation in other metazoans. Cell 37: 403-8

McGinnis, W., Levine, M. S., Hafen, E., Kuroiwa, A., Gehring, W. J. 1984b. A conserved DNA sequence in homeotic genes of the Drosophila Antennapedia and bithorax complexes. Nature 308: 428-33

McGrath, J., Solter, D. 1984. Completion of mouse embryogenesis requires both the maternal and paternal genomes. Cell 37: 179-83

McGrath, J., Solter, D. 1986. Nucleocytoplasmic interactions in the mouse embryo. J. Embryol. Exp. Morphol. 97: 277-89

Melton, D. A. 1985. Injected anti-sense RNAs specifically block messenger RNA translation in vivo. Proc. Natl. Acad. Sci. USA. 82: 144-48

Molineaux, G. S., Engh, H., deFerra, F., Hudson, L., Lazzarini, R. A. 1986. Recombination within the myelin basic protein gene created the dysmyelinating shiverer mouse mutation. Proc. Natl. Acad. Sci USA 83: 7542-46

Monk, M. 1987. Genomic imprinting. Memories of mother and father. Nature 328: 203-4

Mutter, G. L., Grills, G. S., Wolgemuth, D. J. 1988. Evidence for the involvement of the proto-oncogene $c$-mos in mammalian meiotic maturation and possibly very early embryogenesis. EMBO J. 7: 683-89

Reik, W., Collick, A., Norris, M. L., Barton, S. C., Surani, M. A. 1987. Genomic imprinting determines methylation of par- 
ental alleles in transgenic mice. Nature 328: 248-51

Renard, J. P., Babinet, C. 1986. Identification of a paternal developmental effect on the cytoplasm of one-cell-stage mouse embryos. Proc. Natl. Acad. Sci. USA 83: 6883-86

Roach, A., Boylan, K., Horvath, S., Prusiner, S. B., Hood, L. E. 1983. Characterization of cloned cDNA representing rat myelin basic protein: absence of expression in brain of shiverer mutant mice. Cell 34: 799-806

Rosenberg, U. B., Preiss, A., Seifert, E., Jäckle, H., Knipple, D. C. 1985. Production of phenocopies by Krüppel antisense RNA injection into Drosophila embryos. Nature 313: 703-6

Sagata, N., Oskarsson, M., Copeland, T., Brumbaugh, J., Vande Woude, G. F. 1988. Function of $c$-mos proto-oncogene product in meiotic maturation in Xenopus oocytes. Nature 335: 519-25

Saiki, R. K., Scharf, S., Falcona, F., Mullis, K. B., Horn, G. T., et al. 1985. Enzymatic amplification of beta-globin genomic sequences and restriction site analysis for diagnosis of sickle cell anemia. Science 230: $1350-54$

Sapienza, C., Peterson, A. C., Rossant, J., Balling, R. 1987. Degree of methylation of transgenes is dependent on gametes of origin. Nature 328: 251-54

Scott, M. D., Weiner, A. J. 1984. Structural relationships among genes that control development; sequence homology between the Antennapedia, Ultrabithorax, and fushi tarazu loci of Drosophila. Proc. Natl. Acad. Sci. USA 81: 4115-19

Searle, A. G., Beechey, C. V. 1978. Complementation studies with mouse translocations. Cytogenet. Cell Genet. 20: 282303

Searle, A. G., Beechey, C. V. 1985. Aneuploidy: etiology and mechanisms, eds. V. L. Dellarco, P. E. Voylek, A. Hollaender, 3: 23-27. New York: Plenum. pp. 363-76

Solter, D. 1987. Inertia of the embryonic genome in mammals. Trends Genet. 3: 2327

Stacey, A., Bateman, J., Choi, T., Mascara, T., Cole, W., et al. 1988. Perinatal lethal osteogenesis imperfecta in transgenic mice bearing an engineered mutant pro- $\alpha$ l (I) collagen gene. Nature 332: 131-36

Strickland, S., Huarte, J., Belin, D., Vassalli, A., Rickles, F. J., et al. 1988. Antisense RNA directed against the $3^{\prime}$ noncoding region prevents dormant mRNA activation in mouse oocytes. Science 241: 68084

Surani, M. A., Barton, S. C., Norris, M. L. 1984. Development of reconstituted mouse eggs suggests imprinting of the genome during gametogenesis. Nature 308: 548-50

Surani, M. A., Barton, S. C., Norris, M. L. 1986a. Nuclear transplantation in the mouse: heritable differences between parental genomes after activation of the embryonic genome. Cell 45: 127-36

Surani, M. A. 1987. Experimental Approaches to Mammalian Embryonic Development, eds. J. Rossant, R. A. Pederson. pp. 401-36. New York: Cambridge

Surani, M. A., Reik, W. Norris, M. L., Barton, S. C. 1986b. Influence of germline modifications of homologous chromosomes on mouse development. $J$. Embryol. Exp. Morph. 97: 123-36(Suppl.)

Swain, J. L., Stewart, T. A., Leder, P. 1987. Parental legacy determines methylation and expression of an autosomal transgene: a molecular mechanism for parental imprinting. Cell 50: 719-27

Thompson, S., Clarke, A. R., Pow, A. M., Hooper, M. L., Melton, D. W. 1989. Germ line transmission and expression of a corrected HPRT gene produced by gene targeting in embryonic stem cells. Cell 56: 313-21

Weintraub, H., Izant, J. G., Harland, R. M. 1985. Anti-sense RNA as a molecular tool for genetic analysis. Trends Genet. 1: 22 25

Wilkinson, D. G., Peters, G., Dickson, C., McMahon, A. P. 1988. Expression of the FGF-related proto-oncogene int-2 during gastrulation and neurulation in the mouse. EMBO J. 7: 691-95

Wolgemuth, D. L., Behringer, R. R., Mostoller, M. D., Brinster, R. L., Palmiter, R. D. 1989. Transgenic mice overexpressing the mouse homeobox containing gene Hox 1.4 exhibit abnormal gut development. Nature 337: 464-67

Woychik, R. P., Stewart, T. A., Davis, L. G., D'Eustachio, P., Leder P. 1985. An inherited limb deformity created by insertional mutagenesis in a transgenic mouse. Nature 318: 36-40

Zimmer, A., Gruss, P. 1989. Production of chimaeric mice containing embryonic stem (ES) cells carrying a homeobox $\mathrm{Hox}$ 1.1 allele mutated by homologous recombination. Nature 338: 150-53 
$\mathrm{X}$ CONTENTS (continued)

Membrane Traffic in Endocytosis: Insights from Cell-FreE Assa Ys, Jean Gruenberg and Kathryn E. Howell

The BIOGENESIS OF Lysosomes, Stuart Kornfeld and Ira Mellman

INDEXES

Subject Index

Cumulative Index of Contributing Authors, Volumes 1-5

Cumulative Index of Chapter Titles, Volumes 1-5 


\section{CONTENTS}

Control of Protein Exit from the Endoplasmic Reticulum, Hugh R. B. Pelham

Origin AND Evolution OF Mitochondrial DNA, Michael W. Gray

The Chloroplast Chromosomes in Land Plants, Masahiro Sugiura

Tenascin: An Extracellular Matrix Protein Prominent in Specialized Embryonic Tissues and Tumors, Harold $P$. Erickson and Mario A. Bourdon

Growth Factors in Early EMbryogenesis, D. A. Melton and Malcolm Whitman

Dynein Structure And Function, Mary E. Porter and Kenneth A. Johnson

COMmUNiCATION BETWEEN MitochONDRIA AND THE NUCLEUS IN THE Regulation of Cytochrome Genes IN THE YeAST SACCHAROMYCES CEREVISIAE, Susan L. Forsburg and Leonard Guarente

Molecular Genetics of Development Studied in the TransGenic Mouse, Heiner Westphal and Peter Gruss

INITIATION OF EUKARYotic DNA REPLICATION IN Vitro, Bruce Stillman

Lipid Traffic in Animal Cells, Gerrit van Meer

Protein Oligomerization in the Endoplasmic Reticulum, Stella M. Hurtley and Ari Helenius

Drosophila Extracellular Matrix, J. H. Fessler and L. I. Fessler

Simple and Complex Cell Cycles, Fred Cross, James Roberts, and Harold Weintraub

The Interleukin 2 Receptor, Kendall $A$. Smith

Biogenesis of THe Red Blood Cell Membrane-Skeleton and THE CONTROL OF ERYTHROID MORPHOGENESIS, Elias Lazarides and Catherine Woods 